Victorino Farga C.

\title{
Tuberculosis, lo que hay que saber
}

\author{
Symposium on Tuberculosis in adults. Winter meeting, Chilean Society of Respiratory
} Diseases

Resumen de las presentaciones del Módulo Adultos del Simposio Tuberculosis, efectuado durante las Jornadas de Invierno de la Sociedad Chilena de Enfermedades Respiratorias (5/Julio/ 2008). Se puede acceder a la versión completa, en video, de todas ellas, incluyendo el Módulo Pediátrico, en www.serchile.cl (entrar en: material eventos anteriores; marcar: 2008, y marcar: Jornadas).

1. Epidemiología de la Tuberculosis en Chile y el mundo. Hacia la erradicación de la enfermedad

\section{Dr. Victorino Farga C.}

La situación actual de la endemia tuberculosa a nivel mundial sigue siendo muy insatisfactoria. En parte por la epidemia del SIDA y en buena parte por el explosivo crecimiento de la población mundial, dentro de un contexto de Programas de Control muy insatisfactorios y del aumento de las poblaciones de riesgo (pobreza, inmigrantes), el número de enfermos ha seguido aumentando en muchos países.

Han pasado 15 años desde que en Abril de 1993 la Organización Mundial de la Salud (OMS), declaró la Tuberculosis como una Emergencia Global; sin embargo, según su último informe, en el año 2006, hubo 9,2 millones de casos nuevos de tuberculosis y 1,7 millones fallecieron por esta enfermedad. La incidencia de casos nuevos de tuberculosis, en todas sus formas, alcanzó la increíble tasa de 139 casos por 100.000 habitantes, como promedio mundial. Es evidente que estamos muy lejos de acercarnos a la "erradicación" de la tuberculosis; cuando más podremos lograr la eliminación de esta enfermedad, como problema de Salud Pública $(<5$ casos/100.000 habitantes), en el curso de una generación.

La estrategia de la OMS y de la Unión Internacional Contra la Tuberculosis (UICT), la lla- mada Estrategia DOTS (Direct Observed Treatment Short Course) o sea Tratamiento Directamente Supervisado de Corta Duración, ha demostrado ser muy exitosa cuando se aplica adecuadamente $\mathrm{y}$, sin embargo, la tuberculosis se niega a batirse en retirada.

La Estrategia DOTS, mucho antes que fuera planteada por las organizaciones internacionales, es básicamente la misma que se ha venido aplicando en Chile, con otros nombres, durante los últimos 40 años, a través del Programa Nacional de Control de la Tuberculosis del Ministerio de Salud (PCT). Con la aplicación sostenida de este programa y sus constantes perfeccionamientos, Chile ha pasado a ser uno de los pocos países de América, que se está acercando a la llamada etapa avanzada de eliminación de la enfermedad, que es cuando la incidencia de todas las formas de tuberculosis, desciende bajo 10 casos por 100.000 habitantes.

Sin embargo, no todo es tan perfecto, ya que durante el último quinquenio la tuberculosis, que venía descendiendo 7\% por año, ha experimentado un disminución insatisfactoria de $4,9 \%$ en el 2006, lo que debe ser considerado como una campanada de alarma.

Además, esta enfermedad es un ejemplo más de la inequidad propia de nuestra sociedad. Así, un análisis epidemiológico efectuado por el Dr. Manuel Zúñiga, a cargo del PCT, muestra las grandes diferencias en la incidencia de la tuberculosis en las distintas provincias de Chile. En tanto hay regiones, como San Felipe o la zona Oriente de Santiago, con tasas de tuberculosis comparables con las más favorables de cualquier país desarrollado, existen otras, notablemente en los extremos del país, como Arica, Iquique y Magallanes, con tasas de incidencia tres veces más altas que las de menor endemia y el doble del promedio nacional".

Es evidente que hace falta aumentar los esfuerzos para lograr una de las metas del Ministerio de Salud, que es alcanzar la etapa avanzada de eliminación en el año 2010. Esencialmente, 
es necesario intensificar la localización de casos de tuberculosis, concentrando el programa en los grupos de riesgo, como se analizará con más detalle en las próximas presentaciones.

Se comentan los nuevos desafíos que presenta el manejo de la tuberculosis: la asociación TBC/SIDA y la aparición de epidemias de Tuberculosis Multi Drogo Resistente (MDR TB), es decir resistentes a isoniacida y rifampicina; de Tuberculosis Extensivamente Resistentes (XDR TB), que son resistentes a la isoniacida y rifampicina $\mathrm{y}$, además, a alguna quinolona y a algún aminoglicósido inyectable (kanamicina, amikacina, capreomicina), muy difíciles de tratar, y Tuberculosis Extremadamente Resistentes (XXDR TB), resistentes a casi todas las drogas antituberculosas, lo que las hace prácticamente incurables.

Igualmente, es necesario mejorar la eficiencia del tratamiento de los casos nuevos de tuberculosis, disminuyendo sus principales limitaciones: su elevada letalidad y el alto porcentaje de pacientes que lo abandonan antes de completarlo.

\section{Etiopatogenia y Diagnóstico de la Tuberculosis pulmonar y extrapulmonar}

\section{Dr. Pablo Marcone E.}

Los bacilos tuberculosos son transmitidos por las gotitas de Pflügger, desde un paciente enfermo a los pulmones de sus contactos, donde son atrapados por los macrófagos alveolares y llevados a los ganglios hiliares pulmonares, desde donde pueden diseminarse por vía hematógena determinando "bacilemias silenciosas", que los siembran en los diferentes parénquimas.

Podríamos considerar diferentes alternativas de respuesta del huésped. La primera y más feliz para nosotros, es que los sistemas de defensa inespecíficos sean tan eficientes o los bacilos tan poco virulentos o escasos, que sean eliminados antes de despertar el sistema inmune, de modo que ni siquiera ocurra la infección. Pero, lo más frecuente es que se produzca la infección. Cuando ésta se presenta en el contexto de algún grado de inmunodepresión fisiológica, especialmente en niños pequeños, puede determinar enfermedad. En este caso lo frecuente es el desarrollo de una tuberculosis primaria, la mayoría de los casos poco sintomática.

Estas dos situaciones son las más frecuentes, en el primer caso sin trascendencia práctica (curación sin infección), pero en el segundo el resultado puede ser muy dramático, con progre- siones locales y diseminaciones primarias que pueden determinar las formas más graves de la enfermedad: tuberculosis miliar y meningitis tuberculosa.

En los niños el diagnóstico de tuberculosis pulmonar primaria o post primaria es más difícil y debe considerar como primer elemento de orientación el antecedente epidemiológico y el resultado del estudio de contactos. Las manifestaciones clínicas son bastante inespecíficas y, aunque la radiología evidencia el compromiso pulmonar en la mayoría de los casos, siempre deben practicarse los estudios bacteriológicos, en busca de la comprobación etiológica.

En los pacientes inmunodeprimidos, con SIDA, frecuentemente aparecen adenopatías hiliares y mediastínicas y el diagnóstico bacteriológico se hace más difícil. En estos casos, la búsqueda etiológica pasa por la toma de hemocultivos para Mycobacterias. Frecuentemente es necesario además recurrir a estudios más invasivos, por fibrobroncoscopía, en búsqueda de agentes oportunistas.

Lo más frecuente es que la infección tuberculosa se exprese por el desarrollo de inmunidad celular e hipersensibilidad retardada, que determinan una infección latente. Para el diagnóstico de esta condición, en nuestro medio se emplea la reacción de tuberculina (PPD).

La interpretación de un PPD depende de los factores de riesgo de desarrollar una tuberculosis que tenga el sujeto testeado. La Asociación Americana del Tórax (ATS) sugiere que un PPD se interprete como positivo en las siguientes condiciones:

1) Desde $5 \mathrm{~mm}$ de induración cuando los factores de riesgo son importantes (VIH positivos, contactos recientes, lesiones radiológicas fibróticas sugerentes de tuberculosis inactiva, inmunosupresión crónica, por ejemplo por empleo de prednisona $15 \mathrm{mg} /$ día por más de 30 días);

2) Con más de $10 \mathrm{~mm}$, en los con riesgo intermedio (inmigrantes, niños menores de 4 años, drogadictos endovenosos y residentes o empleados de instituciones sometidas a riesgo de transmisión de la enfermedad, como prisiones, hospitales, hogares de ancianos y laboratorios de tuberculosis), $\mathrm{y}$

3) Con más de $15 \mathrm{~mm}$ en personas sin factores de riesgo de exposición o de hacer tuberculosis a los cuales, por lo demás, no se les debería practicar el PPD.

Es sabido que la técnica de tuberculina y su interpretación tiene muchas limitaciones. Por esto, en los últimos años se han creado méto- 
dos de medición de la infección tuberculosa más específicos y sensibles que el PPD, basados en la liberación de interferón gama por parte de linfocitos sensibilizados de la sangre, cuando son estimulados in vitro con antígenos de bacilo tuberculoso más específicos que el PPD (ESAT4 y CFP-10). Estas técnicas ya se han estandarizado y comercializado (ELISPOT y QUANTIFERON TB-GOLD) y tienen la ventaja de excluir la positividad de quienes han sido vacunados por BCG, así como a la gran mayoría de los que han sido infectados por micobacterias ambientales. Sería de gran utilidad en nuestro país, ir introduciendo estas tecnologías más modernas, aplicables a casos seleccionados.

Finalmente, alrededor de un $10 \%$ de los infectados desarrollará la enfermedad, precozmente (antes de los 2 años) o tardíamente, a lo largo de toda la vida, siendo los principales factores de riesgo la existencia de enfermedades anergizantes: infección VIH; diabetes; inmunodepresión; insuficiencia renal y otras que debilitan la inmunidad general, como cánceres, o local como la silicosis.

Aunque la radiología de tórax es el método más sensible para plantear el diagnóstico de tuberculosis pulmonar, es la bacteriología la que permite hacer el diagnóstico específico: Sólo con la baciloscopía de expectoración se logra confirmar o hacer el diagnóstico, hasta en el $70 \%$ de ellos, y con el cultivo otro $20 \%$. Alrededor del $10 \%$ de los casos escapan al diagnóstico bacteriológico y deben ser derivados a centros especializados para su confirmación por otros métodos.

Las técnicas bacteriológicas se han enriquecido con los medios de cultivo líquidos y con el desarrollo de nuevos procedimientos de diagnóstico basados en la biología molecular, en general más sensibles y específicos. Por ejemplo, el estudio con sondas genéticas, algunas ya disponibles en el Instituto de Salud Pública de Chile, permite no sólo identificar el tipo de micobacteria causante de la enfermedad, sino también conocer su perfil de resistencia frente algunas drogas.

En el Instituto Nacional del Tórax (INT) se ha comenzado a emplear una técnica validada y comercializada de amplificación de ADN, para identificar bacilos en diferentes tipos de muestras. Estos métodos que ya se están usando en la medicina privada, donde se atiende una población con una incidencia de tuberculosis menor, deberían irse introduciendo, por lo menos en los Centros de Referencia de nuestros Servicios Públicos.

\section{Actualización del Programa Nacional de Control de la Tuberculosis}

\section{Dr. Carlos Peña M.}

Durante todo el siglo pasado se desarrollaron actividades contra la epidemia de tuberculosis que asolaba a Chile, especialmente por parte del Seguro Obrero y después con la promulgación de la Ley de Medicina Preventiva; pero, fue a partir de la creación del Servicio Nacional de Salud en 1952, que fué posible implementar algunas acciones coordinadas para enfrentar la enfermedad en todo el país, lo que se concretó con la creación de un Programa Nacional de Control de la Tuberculosis (PCT) el 6 de Junio de 1973.

El PCT es un programa de salud pública descentralizado, con cobertura nacional y normas técnicas aplicables a los sistemas de salud público y privado que se detallan en un manual ministerial.

Toda la población es beneficiaria de las actividades del PCT, independiente de la previsión, con gratuidad para la pesquisa bacteriológica y tratamiento de todas las formas de la enfermedad.

El PCT tiene 3 niveles, Central, Intermedio y Local, cuyas funciones se detallan en el Manual del PCT.

Los objetivos específicos del PCT y su grado de cumplimiento, son:

1. Cobertura de vacunación BCG del Recién Nacido de $100 \%$. La cobertura actual es satisfactoria $(98 \%)$.

2. Diagnóstico de $\geq 70 \%$ de la incidencia estimada de tuberculosis pulmonares bacilíferas. Este objetivo se cumple.

3. Curación de $\geq 90 \%$ de los casos de tuberculosis diagnosticados. Este objetivo no ha logrado cumplirse. La curación de casos nuevos alcanzó sólo el $83 \%$ en la cohorte de casos pulmonares bacilíferos vírgenes a terapia del 2006, debido al elevado número de abandonos $(7,2 \%)$ y fallecidos $(7,3 \%)$.

4. Cobertura del estudio de contactos de tuberculosis pulmonar bacilífera e infantil $\geq 90 \%$. Este objetivo ha ido mejorando hasta llegar a 80\% en la Región Metropolitana en 2007.

5. Reducción anual de la incidencia de la tuberculosis en todas las formas $>7 \%$. Este objetivo no se ha cumplido en los últimos años (4,9\% en 2007), lo que atenta con el objetivo de alcanzar la etapa de eliminación avanzada en 2010. 


\section{Factores que dificultan las actividades del PCT}

Los factores que dificultan y reducen el éxito del PCT son la alta rotación de profesionales de la salud en la atención primaria, las dificultades para la supervisión, las condiciones de deterioro socioeconómico de algunos pacientes, la falta de participación de algunos equipos de salud y la existencia de numerosos grupos de riesgo.

Alrededor del $8-10 \%$ de los enfermos tuberculosos fallece anualmente. El análisis de las auditorías de fallecidos, realizadas en la región metropolitana, muestra un predominio masculino. Los casos con tuberculosis pulmonar bacilífera consultan tardíamente y condicionan una demora en el diagnóstico y una mayor letalidad precoz, en la fase diaria de terapia. Otros factores deletéreos conocidos son: edad avanzada, daño hepático previo, toxicidad severa a drogas, coinfección VIH, patologías crónicas asociadas y malas condiciones socioeconómicas. (Aunque algunas auditorías han demostrado que en la mitad de los casos la causa de muerte no se debió a tuberculosis).

El PCT está dirigiendo la búsqueda de casos de tuberculosis hacia sectores de riesgo en la comunidad (pesquisa activa), lo que ha permitido identificar grupos especiales, como los reclusos, por ejemplo, que tienen tasas especialmente elevadas. De la misma manera, cuando se evalúa la situación epidemiológica a nivel comunal, pueden detectarse zonas de mayor incidencia que permanecen ocultas al considerar sólo los promedios por servicio o regiones. Hay que identificar estas áreas para intensificar en ellas los esfuerzos de localización de casos.

El comportamiento epidemiológico y social de esta enfermedad y el análisis de las variables asociadas permiten identificar situaciones donde existe mayor probabilidad de encontrar casos mediante la búsqueda activa en grupos de riesgo: adultos $>65$ años, contactos de casos bacilíferos, pacientes VIH (+), inmigrantes, reclusos, enfermos "en situación de calle" y de hospederías, pueblos originarios, pacientes psiquiátricos, diabéticos, enfermos con EPOC, personal de salud y unidades vecinales de comunas con mayor incidencia.

\section{Refuerzo de las Estrategias del PCT}

La situación actual hace necesaria una focalización y profundización de las actuales estrategias del PCT. Las áreas de diagnóstico, prevención y tratamiento deben fortalecerse, especialmente en capacitación, supervisión y evaluación. Las estrategias esenciales son:

1. Incrementar la detección de casos entre los consultantes con síntomas respiratorios de la atención primaria, la comunidad y el extrasistema.

2. Mejorar los resultados del tratamiento, mediante estrategias que eviten los abandonos (subvención de transporte y alimentos, consejo familiar, evaluación mental, educación reforzada de los pacientes, etc), para asegurar el cumplimiento de la terapia.

3. Prevención: Aumentar el cumplimiento de los estudios de contactos (radiografías de tórax, PPD, evaluación por pediatras de referencia); quimioprofilaxis (contactos menores de 5 años, VIH con PPD $\geq 5 \mathrm{~mm}$, inmunosuprimidos), y protección del personal de salud con riesgo de infectarse.

4. Capacitación permanente: A todo el personal sanitario que directa o indirectamente participa en alguna de las actividades del PCT, incluido el personal del extrasistema.

5. Supervisión: Esta es una actividad indelegable para todos los Encargados del PCT a nivel intermedio y local.

6. Coordinación intersectorial: Las actividades del PCT se pueden ver facilitadas cuando se obtiene la colaboración comunitaria, con líderes y representantes de grupos sociales y de entidades de acción social (Chile solidario, etc).

\section{Proyecciones del PCT}

Es útil agregar que entre las principales medidas que el Ministerio está impulsando, están las disposiciones que asignan a los Directores de los Servicios de Salud una responsabilidad central en el cumplimiento de las actividades del programa. En este mismo sentido apunta la asignación de responsabilidades a nivel de los Seremis de Salud, en cuanto a la constitución de los Comités Regionales de Tuberculosis y a las actividades extra-sectoriales necesarias para facilitar la focalización de las acciones en grupos de alta vulnerabilidad.

En estos momentos se requiere de mayores esfuerzos para el control de la tuberculosis. Es necesario para este objetivo la participación de todos los sistemas de salud y de la comunidad. Una mayor difusión de la importancia que sigue teniendo esta enfermedad en Chile puede ser motivadora para los equipos de salud; facilitaría la gestión de los directivos y mejoraría los resultados de las actividades de control.

Es necesario mantener la estructura del PCT en todos los Servicios de Salud y supervisar el cumplimiento de las normas técnicas para lograr que en el plazo más breve posible alcance- 
mos la soñada meta de tener un "País libre de Tuberculosis".

\section{Evaluación y manejo de los abandonos, fracasos y multirresistencia}

\section{Dr. Juan Carlos Rodríguez D.}

El abandono del tratamiento en tuberculosis es uno de los factores más importantes en el fracaso de una quimoterapia teóricamente perfecta. Depende de factores que son de responsabilidad del paciente, factores que se relacionan con la toxicidad de las drogas, y otros derivados de la organización de los equipos de salud. Los pacientes, con adicción a drogas, los alcohólicos y los que no tienen domicilio fijo, son los más propensos a abandonar la terapia.

En nuestro país el porcentaje de abandono de los enfermos nuevos en tratamiento ha estado frecuentemente sobre el 10\%; después de sucesivas intervenciones se ha ido reduciendo, alcanzando el 5,6\%, en la cohorte de 2006.

En cambio, el abandono entre los casos antes tratados, es decir entre las recaídas y abandonos de tratamiento, es siempre superior al $10 \%$. Especialmente los "abandonadores recuperados" vuelven a abandonar en casi la mitad de los casos.

Las Normas del Programa de Control de la Tuberculosis (PCT), establecen que frente a un abandono, después de más de 4 semanas de tratamiento, si el paciente vuelve con baciloscopías positivas, debe reiniciar la terapia como día 0 ; en cambio, si vuelve con baciloscopías y cultivos negativos, se le completarán las dosis que le faltaban a su esquema original; pero, si vuelve con baciloscopías y cultivos negativos, después de 3 meses de no recibir tratamiento, debe ser controlado bacteriológicamente cada 3 meses y cumplido un año, se debe considerar el caso como inactivo y curado, pese al tratamiento incompleto.

Los fracasos de tratamiento, de acuerdo a las normas del PCT, se producen cuando un paciente persiste con baciloscopías positivas hasta el $5^{\circ}$ mes de la terapia o cuando éstas vuelven a hacerse positivas después de haberse negativizado. La confirmación de fracaso requiere de su comprobación con el cultivo. Con los esquemas actuales las tasas de fracasos en Chile son muy bajas, inferiores al $1 \%$, en los enfermos que siguen regularmente sus controles.

La resistencia a las drogas en los enfermos llamados "vírgenes de tratamiento" (VT), es decir en los casos nuevos, se ha mantenido a lo largo de los años en alrededor del 10\%. Entre los medicamentos, la estreptomicina, como ocurre en todo el mundo, probablemente por ser la droga más utilizada en el pasado, es la que mantiene cifras de resistencia sostenidas más altas, cercanas al $10 \%$; le sigue la resistencia a la isoniacida (3,9\% en el año 2006). La Tuberculosis MultiDrogo Resistente (MDR) primaria, es decir con resistencia a isonicida y rifampicina, en pacientes nunca antes tratados, es muy baja entre nosotros, siempre inferior al $1 \%$.

En los enfermos "antes tratados" (AT), la resistencia adquirida global, que incluye las recaídas, los abandonos y los llamados "controles de tratamiento", donde están los fracasos bacteriológicos, aunque ha venido descendiendo en forma sostenida en nuestro país, aun se mantiene sobre el $20 \%$ (22\% en 2006), siendo la resistencia adquirida a la isoniacida de $12,6 \% \mathrm{y}$ la MDR adquirida del 7,7\% en el mismo año.

Las únicas formas de generar resistencia es con monoterapia directa o encubierta y con irregularidades en el tratamiento, particularmente en la fase bisemanal, ya que la diferente duración en el efecto post-antibiótico de la isoniacida y la rifampicina, puede generar resistencia a ésta última.

Un problema especial es el de la tuberculosis MultiDrogoResistente (MDR) que se asocia a mal pronóstico, en el sentido de que las posibilidades de curación bajan significativamente. En el último tiempo se han descrito las Tuberculosis Extensivamente Resistentes (XDR), en las que además de la resistencia a isoniacida y rifampicina, hay resistencia a una quinolona y a un aminoglucósido, lo que les confiere un considerable peor pronóstico.

En la evaluación de una posible resistencia bacteriana, lo más importante es hacer una adecuada anamnesis de las drogas empleadas. Los estudios de sensibilidad in vitro, están bien validados para la isoniacida, rifampicina y estreptomicina, pero no tienen la misma buena correlación clínica con las demás drogas. Hoy día existe la posibilidad de determinar rápidamente la resistencia a la rifampicina con técnicas de biología molecular. El gen que codifica la resistencia a rifampicina es único y fácil de detectar; en cambio, la resistencia a la isoniacida depende de varios genes, lo que hace más complejo su estudio.

Las posibilidades de curar a un tuberculoso con MDR, son de alrededor del 50\%, de acuerdo a las comunicaciones de la literatura; en cambio, para la tuberculosis XDR, son muy inferiores. 
Para tratar un paciente con tuberculosis MDR, se deben seguir algunos principios. En primer lugar, hacer un buen diagnóstico, con una adecuada anamnesis de las drogas utilizadas y un buen estudio de sensibilidad. Enseguida, deben emplearse al menos tres medicamentos nuevos, nunca antes recibidos por el enfermo, incluyendo entre ellos un aminoglucósido. El tratamiento debe prolongarse durante 18-24 meses. Una regla de oro es que no se debe agregar nunca una droga nueva a un esquema que esté fracasando.

El retratamiento de los pacientes resistentes está bien estandarizado, en Chile, según las Normas del PCT.

\section{La búsqueda de nuevos tuberculosos: Prevención y acción en la comunidad y hospitales}

\section{Dr. Fernando Tabilo P.}

La prevención de la tuberculosis depende de su diagnóstico y tratamiento oportunos, porque la vacuna $\mathrm{BCG}$ sólo confiere protección frente a la meningitis tuberculosa y las diseminaciones hematógenas en los niños. Por otra parte, la quimioprofilaxis tiene muchas limitaciones operacionales; sin embargo, debe ser indicada por lo menos en los infectados recientes (contactos) y en los infectados antiguos con factores de riesgo, especialmente coinfectados VIH.

La gran mayoría de los enfermos tuberculosos se encuentra entre los tosedores de más de tres semanas de duración, que consultan espontáneamente en los Servicios de Salud. Solicitar dos exámenes de expectoración, para practicar en ellos dos baciloscopías y un cultivo, es sencillo, rápido y gratuito; la solicitud puede hacerla incluso personal no médico.

Sin embargo, sólo uno de cada tres médicos generales, en la atención primaria, aprovecha la oportunidad diagnóstica y pide baciloscopías en la primera entrevista del tosedor potencialmente tuberculoso, cortando así la cadena de transmisión. Dos tercios de esos profesionales pensó que el paciente tenía una simple bronquitis y este error tendrá varias consecuencias: el bacilífero seguirá diseminando la enfermedad en su comunidad, pudiendo enfermar a sus hijos, exponiendo a sus vecinos a respirar el mismo aire ahora contaminado de las salas de espera, hacinadas de público, especialmente en los meses de invierno, mientras su lesión pulmonar progresa y puede llevarlo a la muerte.

Por otra parte, el área diagnóstica de los nuevos casos de tuberculosis, está migrando en los últimos años desde la atención primaria hacia los servicios de urgencia, departamentos broncopulmonares especializados y médicos privados; esto hace necesario focalizar la búsqueda de casos en los grupos de riesgo, priorizando las encuestas baciloscópicas en los contactos de enfermos bacilíferos, adultos mayores, vagabundos, reclusos, VIH (+), inmunodeprimidos, inmigrantes y pueblos originarios.

La desigualdad geográfica en tuberculosis permite identificar barrios abundantes en casos bacilíferos, que conforman racimos (clusters) de enfermos, a los que se debe acceder con cautela para no aumentar su estigmatización.

Por otra parte, los tuberculosos desconocidos, consultantes de los hospitales generales, constituyen un riesgo tanto para otros pacientes, como para el personal de salud, especialmente en los servicios de urgencia y salas de broncoscopía.

Además, se ha podido establecer que la mitad de los tuberculosos bacilíferos tienen una enfermedad prexistente y estarán este mes asistiendo a los consultorios generales y a los Policlínicos de Diabetes, Salas ERA, Infectología y Otorrinolaringología, según se logró demostrar en un Servicio de Salud de la Región Metropolitana, al encuestar a los pacientes pulmonares demostrados bacteriológicamente durante la primera semana de su diagnóstico.

Los servicios de urgencia no hacen pesquisa de tuberculosis, pero todos los meses encuentran casos pulmonares; por su propia protección, deberían idear un sistema permanente de búsqueda de casos en sus consultantes.

Es un error considerar como resuelto el problema de la tuberculosis en nuestro país. 